\title{
LA PRESENCIA DEL CUERPO AUSENTE EN LAS TENSIONES ENTRE LENGUAJES: LA TEMPORALIDAD VIVIDA EN EL ESPACIO EN LA OBRA "COMUNICACIONES" DE MARGARITA PAKSA
}

\author{
Mónica Reinoso Recalde \\ Gabriela Santander
}

Fecha de recepción: abril 2016

Fecha de aceptación: mayo 2016

\begin{abstract}
Resumen:
El propósito de este ensayo es analizar cómo las relaciones entre lenguajes permiten crear posibles realidades en la obra "Comunicaciones" de Margarita Paksa, a partir del acto creativo de la percepción, mediante las evidencias y juego de opuestos de los que está compuesta la obra, la cual se configura en el ámbito instalativo, como proceso inacabado y en constante devenir a completarse en la conciencia del espectador. Se diferencian tres momentos clave que aluden al problema de lo temporal como constitutivo de lo procesual: la producción, la exhibición y percepción de la obra mediante el uso del documento y el desbordamiento del arte a otros campos de conocimiento borrando las fronteras entre disciplinas artísticas.

Se indaga sobre lo virtual presente en el trabajo de Paksa, las significaciones resultantes de la actualización constante que se da por las relaciones imbricadas entre los significantes que conforman la instalación, los espectadores y la misma ausencia-presencia de la artista, de su cuerpo ausente en lo visual y lo sonoro.
\end{abstract}

\begin{abstract}
:
This work study artistic languages and how its relation allows creating different realities in the installation "Comunicaciones", made by Margarita Paksa. With a creative act of perception, this artist uses evidence and the game of opposites to set up a time-space installation, which in the end, is a nonfinished process. There are three main moments in Margarita Paksa's work: production, exhibition, and perception. These moments develop the problem of, how the temporality makes procedures. Paksa's work discusses artistic manifestations in the 60's, in Argentina, where people used art to approach other fields in order to connect. Paksa exposes virtuality and the probability of its reality. The artist shows presence using absence, she shows one absent body using both: visual language and sounds.
\end{abstract}

Palabras claves: cuerpo, experiencia estética, conceptualismo, instalación, lenguajes.

Keywords: body, aesthetic experience, conceptualism, installation, languages. 


\section{Autoras:}

Mónica Reinoso Recalde, Quito, 1981. Ballet Ecuatoriano de Cámara, exploración con otras escuelas como Jazz, Flamenco y Tango. Formación universitaria en Biología en la Universidad Católica de Quito, posgrado de especialización en Biología Celular en la Universidad de Campinas, Sao Paulo, Brasil. Capacitaciones en Fotografía Microscópica Electrónica y fotografía artística. Exposición fotográfica en la muestra "Tiempo Detenido" (Imágenes en Danza) en Quito. Investigadora en el campo de la Biología Molecular, docente en Danza y encargada de archivos fotográficos de varios proyectos artísticos en Ecuador. Actualmente maestranda (etapa de tesis) en el Posgrado en Lenguajes Artísticos Combinados de la Universidad Nacional del Arte en Buenos Aires.

Gabriela Santander, Quito, 1984.

Estudios en Artes Visuales en la Universidad Católica de Quito, Maestría “on-line” en Museografía Interactiva y didáctica en Barcelona. Seminarios y talleres de profesionalización: redes colaborativas, performance, arte contemporáneo, pensamiento visual. Participaciones en varios encuentros artísticos con video-arte y video performance en Ecuador, Colombia y Marruecos. Experiencia en el desarrollo de proyectos museográficos. Gestión en arte en La Karakola, casa de experimentación y convivencia artística, proyectos: residencias, ciclos de video arte y actividades artísticas en el barrio San Marcos, Quito. Actualmente maestranda (etapa de tesis) en el Posgrado en Lenguajes Artísticos Combinados de la Universidad Nacional del Arte en Buenos Aires. 
"Convengamos en que ninguna cosa es inteligible por si sola, excepto cuando entra en relación con otra cosa"

(Paksa, 1999)

Desde una perspectiva histórica, las relaciones entre lenguajes artísticos se han dado de manera característica de los procesos de desbordamiento entre disciplinas. Los planteamientos estéticos enmarcados en estas tendencias se podrían ubicar a partir de la segunda mitad del siglo XX, con las exploraciones técnicas y conceptuales, con características particulares en el caso de Latinoamérica y en este caso, Argentina. Por otro lado, está también la búsqueda de la intertextualidad que Fluxus habría abierto, en las prácticas artísticas de la época. Mientras que en el contexto argentino, el desarrollo del arte conceptual tuvo su propio proceso, respondiendo a una realidad local, evidenciándose el peso de los modos de uso particulares, tanto de conceptos como de técnicas y aparatos tecnológicos.

El presente análisis reflexiona en torno a las relaciones y tensiones entre los lenguajes verbal, sonoro, visual y corporal, que permiten crear posibles realidades en la obra "Comunicaciones" de Margarita Paksa, a partir de la experiencia del espectador. experiencia que se construye a base de evidencias y juego de opuestos de los que está compuesta la obra, la misma que se configura en el ámbito instalativo; por lo tanto espacio-temporal, como un proceso inacabado $y$ en constante devenir. Se diferencian tres momentos clave que aluden al problema de lo temporal como constitutivo de lo procesual: la producción, la exhibición y percepción de la obra, y el tiempo de lo documental o del registro. Se indaga sobre lo virtual presente en el trabajo de Paksa, las posibles significaciones resultantes de la actualización constante que se da por las relaciones imbricadas entre los significantes que conforman la instalación, los espectadores y el cuerpo ausente de la artista en lo visual, lo verbal y lo sonoro.

La obra Comunicaciones puede analizarse a partir de la relación con el desbordamiento del arte y de sus disciplinas, hacia la combinatoria de lenguajes en tanto que antecedente de las prácticas artísticas contemporáneas, como planteamiento estético basado en el proceso, la experiencia y la problematización del tiempo, el espacio y el cuerpo mediante la deconstrucción de los mismos, poniendo en evidencia el dispositivo tecnológico como configurador de realidad.

Para realizar el presente análisis, se recurrió a material de archivo disponible en Internet, en la página web de la artista como en canales de Youtube y otras fuentes virtuales. Por otro lado se utilizó el libro de "Proyectos sobre el discurso de mi" de la misma Artista, publicado por Fundación Espigas. Y finalmente, se acudió al Museo Nacional de Bellas Artes de Buenos Aires, en donde tienen expuestos los documentos sonoros, visuales y verbales que constituyen la obra.

Margarita Paksa, es una artista argentina, cuyo trabajo se inscribe en lo multimedia al constituirse por producciones compuestas por elementos presentados en varios soportes. Por otro lado, Paksa es una de las referentes fundadoras de la tendencia del arte conceptual en su país. Su práctica artística se vio también vinculada al Instituto Di Tella en Buenos Aires, entidad que promovía la investigación y la experimentación en el arte, en la década del 60, ubicándose para la época como símbolo de vanguardia cultural y polémica.

La obra "Comunicaciones", a analizar en este caso, fue presentada en la exposición 
denominada Experiencias 68, en dicho Instituto. El uso del término experiencia, según Romero Brest, (quien fue director del Centro de Artes Visuales de dicho Instituto), alude al hecho de que no implica obras terminadas ni definitivas, sino, más bien proyectos de creación dinámica para el observador.

Se podría, decir que "Comunicaciones" es una obra de carácter procesual, conformada por las etapas mencionadas, posibles de ser pensadas como constitutivas de la obra exhibida en tanto que experiencia, a partir del uso de aparatos correspondientes a las tecnologías de la comunicación, evidenciándose una problematización del dispositivo técnico, y por lo tanto, de la construcción de otras realidades, conformando nuevos cuerpos, o así mismo, transformando la percepción del cuerpo vivido.

Durante la producción (no exhibida pero registrada en audio), se dieron varios momentos y elementos, como la construcción de un espacio blanco, con sus ángulos curvos, en una especie de altillo al que se accedía por una escalera. Este ambiente, según describe Paksa en su libro titulado "Proyectos Sobre el Discurso de Mi”, permitía ser habitado por un cuerpo sentado o acostado, explicitando la intención de su utilización para la meditación o el amor.

Es a partir de la experiencia en este espacio, que la artista realizó la grabación sonora titulada "Santuario del Sueño", que sería la descripción verbal y obsesiva de dicho ambiente. Descripción hipnótica y que alude a un estado mental meditativo, apoyado en el vacío visual que provocaría el espacio recreado por la palabra.

Adicionalmente, la artista realizó una grabación sonora de los jadeos de una pareja, teniendo relaciones sexuales, titulada "Candente". El material sonoro fue registrado en un disco de vinilo, (cada grabación en un lado del disco) el mismo que es soporte del diseño visual de dos espirales, que al girar producen un efecto óptico específico.

Como último momento de la etapa previa a la exposición, se emplazó una superficie de $8 \times 4 \mathrm{~m}$ cubierta de arena, frente a la que se dispusieron 2 tocadiscos Winco con auriculares, articulando así la arquitectura de la instalación para ser experimentada.

Ya en la exposición, se destinó un lugar para que el espectador tomara asiento frente a los tocadiscos y a la superficie de arena, de manera que fuese posible acceder a una audición mucho más intima y personal, según la misma artista lo explica. Además, de esta manera el espectador tenía la posibilidad de escuchar las dos grabaciones.

La intervención de lo corporal, realizada esporádica, pero periódicamente, consistió en la impresión sucesiva de los cuerpos de la arista y su pareja, sobre la arena, ambos vistiendo mallas de color negro. Esta acción se realizó el mismo día de la exposición, abandonando luego el lugar, y sería repetida semanalmente. La intervención fue fotografiada y reproducida por el medio gráfico masivo "Primera Plana", una de las pocas revistas de difusión del quehacer artístico en la época.

Las relaciones espacial y temporal, por un lado plantean una especie de escenario a la italiana, y por otro despliegan el presente de un pasado, interpelando al espectador a proyectar su mirada, a partir de las pistas que la artista le provee, mediante el uso del documento, tanto desde el soporte tecnológico como desde la arena, incluso expandiendo el acontecimiento a 
través de un medio de comunicación mediante el registro fotográfico, evidenciando y haciendo uso del carácter fragmentado de la memoria.

De esta manera y en palabras de la artista, la obra constituiría un "balanceo entre lo efímero grabado en la arena, que queda como rastro, y lo perdurable también efímero pero auditivo, bajo la forma del disco.” (Paksa, 1997, p. 76).

Los lenguajes utilizados estarían imbricados entre si, desapareciendo sus límites por la articulación de una experiencia sinestésica, que cobra lugar en la vivencia del espectador dentro de la instalación.

En "Comunicaciones", se hace uso de lo visual constituido por el trabajo con el espacio como material, que involucra significantes como: huellas en la arena, el color y el efecto óptico del movimiento del espiral en el disco, la disposición del mobiliario a ser usado por el público y los tocadiscos con audífonos. Todo lo cual conforma un espacio a ser habitado por el espectador.

En relación con lo sonoro, la obra consta de dos registros auditivos de características diferentes, que inducen al espectador a estados encontrados. "Candente" moviliza los sentidos no solo en la construcción de significado, sino hacia la corporalidad misma del espectador; mientras que "Santuario del Sueño" induce, por otro lado, a un estado pasivo de introspección, buscando alcanzar una suerte de abandono de la corporalidad.

Lo verbal se resuelve a través de la descripción obsesiva de un espacio otro, el que se crea en la duración del relato para inducir su visualización, conjuntamente con la forma de habitarlo.

El cruce de lenguajes sustenta las dimensiones temporal y espacial de la obra al constituirse en la simultaneidad de tiempos, que se expanden en duración, se da como signo-tiempo, como apunta Brea (2003): "la representación se abre al régimen de la duración en su propio interior, se temporaliza internamente" (p. 6). Como si la temporalidad de la obra estuviera hecha de varios tiempos que la atraviesan, en un fluir constante, en la interdependencia con el espectador y en el modo de habitar la instalación, que, en tanto se escucha y se mira, se va enlazando, tejiendo desde las huellas, que no solo pertenecen a un pasado, sino que son reconstruidas incansablemente en el presente, por el mismo espectador y por la artista, que, sistemáticamente, va reiterando la marca de su cuerpo, en eventos efímeros, alcanzables solo a partir del rastro.

En esta experiencia del espectador, dentro de la instalación, la inducción de lo verbal solo es posible a través del carácter sonoro de la enunciación y sobre todo por las posibilidades que brinda el dispositivo técnico, el cual provoca un aislamiento sonoro y por lo tanto espacial y temporal, que aleja al espectador de su realidad fáctica, o media entre ambos. Esta mediación de la realidad implica la transformación en la percepción de lo espacial

El espacio deviene en soporte para la construcción del imaginario del espectador a partir del estimulo sonoro. Se problematiza lo ausente y lo presente, así como lo efímero y lo permanente. La interpelación de estos conceptos, aparentemente opuestos, se pone en marcha cuando a partir del sonido, en el caso de "Candente", hay una inducción a la identificación de una huella que da cuenta de la ausencia de un cuerpo. Cuerpo que se hace presente mediante las marcas visuales y sonoras que combina la obra.

En definitiva, la transformación del espacio ocurre en un nivel cualitativo en la duración de 
la experiencia que es provocada por el cruce de lenguajes.

El desarrollo de la tradición conceptualista basada en el cuestionamiento de la propia idea de obra de arte como objeto, se evidencia en "Comunicaciones", en tanto la aportación del documento, al ser usado como el soporte resultante de dispositivos técnicos y mediáticos que, para la época, marcaron las dinámicas sociales, transformando los ámbitos de lo privado, lo público y las concepciones del tiempo y del espacio. En este caso la obra está marcada por el uso de la grabadora de sonido y el tocadiscos ${ }^{1}$, como aparatos que, en la década del 60 se comercializaban normalmente para el uso doméstico.

"Comunicaciones" es una obra que se constituye en cuanto a las posibilidades que acompañan la experiencia. Todos sus elementos integran un conjunto de aspectos que requieren algún tipo de resolución, al entrar y formar parte de la dinámica de la instalación, la que aparentemente plantea coordenadas espacio temporales estables que se virtualizan. Esto implicaría necesariamente la indeterminación en sus procesos como mecanismo de creación de realidad.

La instalación conforma un modo de habitarla a partir de lo mnemotécnico, caracterísitco del dispositivo técnico utilizado, tanto en los surcos del disco que devienen significantes sonoros, verbales y visuales, así como en la arena que revela las marcas visuales de lo sucedido. Es un espacio en el que se tensiona el tiempo, desarticulándolo en múltiples fragmentos que permiten la vivencia del presente que pasa, y del pasado que es el presente que fue.

1 El tocadiscos utilizado es marca Winco, empresa que comercializó, en Argentina y

Latinoamérica, este tipo de aparatos desde fines de los años 50 hasta principios de los 70 .
$Y$ en la medida en que se habita el espacio, materia de lo instalativo, es articulado por el cuerpo, subjetivado desde las experiencias espacio temporales del espectador, dadas desde la combinación de los lenguajes urdidos por los significantes cuidadosamente seleccionados, $y$ entramados transversalmente por las problemáticas del cuerpo, el que atraviesa y es atravesado por el tiempo y el espacio.

Por otro lado, en tanto la obra resulta hoy en día un bien coleccionable en el ámbito museal, se evidencia su carácter de proceso, que finalmente es un conjunto de documentos, una suerte de nuevas pistas desde las que se llevó a cabo la presente investigación e interpretación.

\section{Referencias}

\section{Bibliografía}

Brea, J. (2003). El tercer umbral. Estatuto de las prácticas artísticas en la era del capitalismo cultural. Murcia: CENDEAC

Levy, P. (1999). Qué es lo Virtual?, Buenos Aires: Paidos - Ibérica.

Paksa, M. (1997). Comunicaciones. En M. Paksa, Proyectos sobre el discurso de mi (p. 74-80), Buenos Aires: Fundación Espigas.

Rosenbaum, A. (2011). Lo que se oculta detrás de un nombre: cruce de lenguajes y apropiaciones disciplinares, En G. Marotta (Dirección), IV Simposio en Lenguajes Artísticos Combinados, Posgrado en Lenguajes Artísticos Combinados, Buenos Aires, Departamento de Artes Visuales, IUNA.

\section{Páginas en Línea}

Cuadra, Á. (2007). La obra de arte en la época de su hiperreproductibilidad digital. Recuperado del Archivo del Observatorio para la CiberSociedad en http://www.cibersociedad.net/archivo/articulo. 
php?art=227 [Consulta: 9 de Octubre de 2015]

Groys, B. (2009). La topología del arte contemporáneo, Antinomies of Art and Culture. Modernity, Postmodernity,Contemporaneity, Duke University Press, (p. 71-80). Recuperado de www. rojas.uba.ar/lipac/biblioteca/groys.pdf [Consulta: 2 de Octubre de 2015]

Valesini, S. (2012). La instalación como dispositivo expositivo y comunicacional. El caso Misión/ Misiones (cómo construir catedrales) de Cildo Meireles en la I Bienal del MERCOSUR. Recuperado del Repositorio Institucional de la UNLP en http://sedici.unlp.edu.ar/ handle/10915/40999 [Consulta: 2 de Octubre de 2015]

\section{Videos}

Paksa, M. Sobre el discurso de mi. Obras 19641994.

Disponible en https://www.youtube.com/ watch?v=jOsOhjOmPgU

[Consulta: 2 de Octubre de 2015]

Paksa, M. (Junio, 2008). Entrevista.

Disponible en https://www.youtube.com/ watch? $v=\mathrm{PwOwu} 6 \mathrm{H} 9-\mathrm{I}$

[Consulta: 2 de Octubre de 2015] 